\title{
Two warehouse inventory policy with price dependent demand and deterioration under partial backlogging
}

\author{
Mohit Rastogi ${ }^{a^{*}}$, S.R. Singh ${ }^{\mathrm{b}}$, Prashant Kushwah ${ }^{\mathrm{a}}$ and Shilpy Tayal ${ }^{\mathrm{b}}$
}

${ }^{a}$ Centre for Mathematical Sciences, Banasthali University, Banasthali, Rajasthan, India ${ }^{b}$ Department of Mathematics, CCS University, Meerut, India

\section{H R O N I C L E A B S T R A C T}

Article history:

Received February 25, 2016

Received in revised format:

March 28, 2016

Accepted August 22, 2016

Available online

August 232016

Keywords:

Inventory

Deterioration

Warehouse

Shortages

Partial backlogging

\begin{abstract}
In today's era of higher competition in the business, there are many conditions such as offered concession in bulk purchasing, seasonality, higher ordering cost, etc., which force a retailer to purchase more quantities than needed or exceed the storage capacity. So in this situation the retailer has to purchase an extra warehouse named as rented warehouse to stock the extra quantity. In this paper an inventory model for deteriorating products with selling price dependent rate is developed. The occurring shortages are assumed to be partially backlogged and cycle time is also variable. The purpose of the development of this model is to compute the amount and time of order which can optimize the total average cost of the system. A solution procedure and numerical example are presented to illustrate the implementation of the proposed study. Sensitivity analysis concerning with distinct system parameters is also presented to demonstrate the model.
\end{abstract}

(C) 2017 Growing Science Ltd. All rights reserved.

\section{Introduction}

Generally it is seen that the enterprisers are forced to buy more than their storage capacities due to offered concession in bulk purchasing, to avoid the ordering cost, etc. In these situations the business enterprises have to purchase a rented warehouse to stock the extra ordered quantity. Normally per unit holding and deterioration costs in rented warehouse are greater than the cost in owned warehouse owing to the additional cost of safeguarding and holding material so the items should be stored first in O.W. and only surplus stock should be stored in R.W. Hence to reduce the total inventory cost it is necessary to finish the stock of rented warehouse first and then to consume the stock in owned warehouse. Also the increased capacity of owned warehouse decreases the total system cost. So while developing the inventory models the study of a two warehouse system cannot be overlooked.

* Corresponding author.

E-mail address: mohitrastogi84@gmail.com (M. Rastogi)

C 2017 Growing Science Ltd. All rights reserved. doi: $10.5267 /$ j.dsl.2016.8.004 
Two warehouses system was first addressed by Hartely (1976) under the assumption that R.W. causes a higher inventory holding cost than owned warehouse. As a result, products in R.W. are shifted to O.W. until stock level in R.W. becomes zero and after that products in O.W. are consumed. Goswami and Chaudhuri (1992) extended this model for shortages and time dependent function of demand rate. They also applied a transportation cost to shift the stock from R.W. to O.W. But this model was developed for non-deteriorating products only. For deteriorating products, a two warehouses inventory system was introduced by Pakkala and Achary (1992). The authors considered backlogging shortages and finite production for such model. Yang (2004) considered the rate of inflation in two warehouse inventory models and presented a model for deteriorating items with allowable shortages. The demand rate is considered as fixed in this model. Dye et al. (2008) studied problem of two storage inventory assuming dynamic demand over finite time horizon. For deteriorating items a two-warehouse inventory model with shortages under inflation was offered by Singh et al. (2009). Jaggi and Verma (2010) presented a two-warehouse system by considering inflationary environment and linear trend in demand. Shortages were permissible and backlogged completely in this model. A two-warehouse inventory system considering time varying deterioration was derived by Sett et al. (2012). The derived model considered in quadratic form as demand increases and by considering finite replenishment rate. Singh et al. (2013) introduced an inventory model of imperfect quality items with inflation under two limited storage capacity. Agrawal et al. (2013) suggested a two warehouse system with ramp-type demand for deteriorating products. To develop this model zero lead-time is considered and shortages are backlogged partially at an unvarying rate. Bhunia et al. (2014) explored a single item, two warehouse deteriorating inventory model with distinct preserving facilities by considering partially backlogged shortages over infinite planning horizon. For the formulation of the model the rate of demand is considered as fixed and well-known and lead time is also assumed as constant. On two-warehouse inventory model, Jaggi et al. (2015) studied the effect of deterioration with imperfect quality. Authors stated retailer was required to hire RW to decrease the losses caused by deterioration with improved preserving facilities, because of not having good facilities in OW. In this study, rate of screening is considered to be more than the demand rate, which means no shortages are permitted. Palanivel et al. (2016) formulated a two warehouse system with non-instantaneously deteriorating items by considering demand rate as stock-dependent. Shortages are permissible and backlogged partially in their model. But the concentration to price sensitive demand is not given in this model.

During the last few decades, many inventory practitioners broadly have studied numerous facets of inventory modeling by assuming demand rate as constant. However in realism, demand of an item has been for all time in a dynamic state. This catches the attention of researchers to feel regarding the variability of demand rate. In the today's competitive market, the selling price of an item is one of the vital factors in choosing the product. The selling price factor accounts for the fact that an increase in the selling price of the commodity discourages a repeat demand. Various demand patterns have been used in the inventory modeling such as constant, time dependent, stock dependent and selling price dependent. Normally it is seen that the selling price of the products is most affecting factor of demand. For illustration, firms may vigorously regulate their prices to enhance demand and increase incomes. Therefore, the product's demand has to depend on the selling price, which makes the study more realistic.

In this area, Wee (1997) presented a replenishment policy for items with a price-dependent demand and a varying rate of deterioration. Mondal et al. (2003) suggested an inventory system of ameliorating items in which demand rate is price dependent. Maiti et al. (2009) presented an inventory model with price-dependent demand for an item in stochastic environment. Singh et al. (2011) introduced a soft computing based inventory model with deterioration and price dependent demand. Jaggi et al. (2014) presented credit financing for deteriorating items in a two-warehouse environment with price-sensitive demand. In this model, shortages were backlogged completely. Tayal et al. (2015) introduced an inventory model for deteriorating items with seasonal products and an option of an alternative market. 
In this model the demand for the products is taken as a function of price and season. Sharma et al. (2015) suggested a deteriorating inventory model by introducing price sensitive demand and shortages. Alfares and Ghaithan (2016) explored an inventory and pricing model by considering price-dependent demand. In this model, holding cost is considered as dependent upon time.

In many of the developed models the attention is not given to the shortages during stock out and if the researchers considered shortages they assumed it completely backlogged or completely lost. Both of these conditions do not satisfy the condition of backlogging completely. Since some customers come back to complete their demand occurring during stock out and some other impatient customers make their purchases from any other places. Dave (1989) presented a lot-size inventory model with allowable shortages and linear trend in demand. Ouyang et al. (1999) developed lead time and ordering cost reductions policies in continuous review inventory systems with partial backordering of occurring shortages. An inventory model for deteriorating items with exponential declining demand and partial backlogging was developed by Ouyang et al. (2005). Singh and Singh (2007) suggested a model with partial backordering and ramp type demand. In this model deterioration follows Weibull distribution (two parameters). Dye et al. (2007) studied pricing and ordering policy with constant rate of partial backlogging for deteriorating products. Chern et al. (2008) studied a partial backlogging lot-size model for deteriorating commodities with fluctuating demand. Skouri et al. (2009) suggested a model by considering ramp type demand, partial backlogging and Weibull deterioration. Taleizadeh and Pentico (2103) introduced an economic order quantity model with a known price increase and partial backordering. Tayal et al. (2014) presented a two echelon supply chain model with effective investment in preservation technology for deteriorating items. In this model, the shortages are allowed and the happening shortages are partially backlogged. Shastri et al. (2015) explored an inventory model by considering trade credit effect and ramp type demand for deteriorating items. Shortages are permitted and unsatisfied demand is backlogged partially, also rate of deterioration is considered as linear increasing function of time. San-José et al. (2015) analyzed an economic order quantity inventory model with partial backordering. During the period of stock out, shortages are permissible and simply a portion of demand is considered as backordered partially. Recently, Khanna et al. (2016) presented an inventory model considering permissible delay in payments with allowable shortages for imperfect quality deteriorating items and occurring shortages are assumed as fully backlogged in this model.

From above literature it is observed that less interest has been paid by the researchers in developing two-warehouse inventory model with price-sensitive demand. So, in this present model we combine all mentioned factors with the selling price dependent rate of demand. This is an EOQ model for deteriorating products with two warehouse and allowable shortages and occurring shortages are considered as backlogged partially. The numerical example and sensitivity analysis are presented to illustrate this study.

\section{Assumptions and Notations}

\subsection{Assumptions}

In order to develop the present model, some specific assumptions used as follows,

1. The replenishment rate is assumed to be infinite.

2. The owned warehouse has a limited capacity of $\mathrm{W}$ units.

3. The rented warehouse has unlimited capacity.

4. The lead time is assumed to be zero.

5. The demand rate is a function of selling price.

6. The items considered in this model are deteriorating in nature.

7. The items are stored in R.W. only after filling owned warehouse.

8. The items kept in R.W. will be consumed first. 
9. The shortages are allowed and partially backlogged.

10. Holding cost per unit in R.W. is greater in comparison of holding cost per unit in O.W.

\subsection{Notations}

The following are the notations used throughout this model.

$\begin{array}{ll}I_{r}(t) & \text { Inventory level at time t in R.W. } \\ I_{o}(t) & \text { Inventory level at time t in O.W. } \\ K & \text { rate of deterioration } \\ a & \text { initial demand rate } \\ b & \text { positive demand parameter } \\ t_{1} & \text { the time at which inventory level in R.W. becomes zero } \\ W & \text { stock capacity of O.W. } \\ v & \text { time at which inventory level becomes zero in O.W. } \\ s & \text { selling price per unit } \\ Q_{1} & \text { initial stock level } \\ Q_{2} & \text { backordered quantity during stock out } \\ T & \text { cycle time } \\ p & \text { purchasing cost per unit } \\ \theta & \text { rate of backlogging } \\ h_{r} & \text { holding cost per unit in R.W. } \\ h_{o} & \text { holding cost per unit in O.W. } \\ d & \text { per unit deterioration cost } \\ c_{2} & \text { per unit shortage cost } \\ c_{3} & \text { per unit lost sale cost } \\ T . A . C . & \text { total average cost }\end{array}$

\section{Mathematical Modelling}

In the beginning $Q$ units are received in stock, out of which $Q_{2}$ units are utilized to satisfy backlogged demand and $Q_{1}$ units are the initial stock level. Since capacity of O.W. is only $W$ units and $Q_{1}>W$, so remaining $\left(Q_{1}-W\right)$ units are stored in a rented warehouse. Now since holding cost in R.W. is greater compared with holding cost in O.W., the items in R.W. will be consumed first. In this duration inventory level in O.W. is reduced because of deterioration only. At $\mathrm{t}=\mathrm{t}_{1}$ inventory level in R.W. becomes zero after satisfying the demand and deterioration. During $\left[\mathrm{t}_{1}, \mathrm{v}\right]$ stock is available only in O.W. At $t=v$ inventory level in O.W. also becomes zero and after that shortage occurs and is shown in Fig .1.

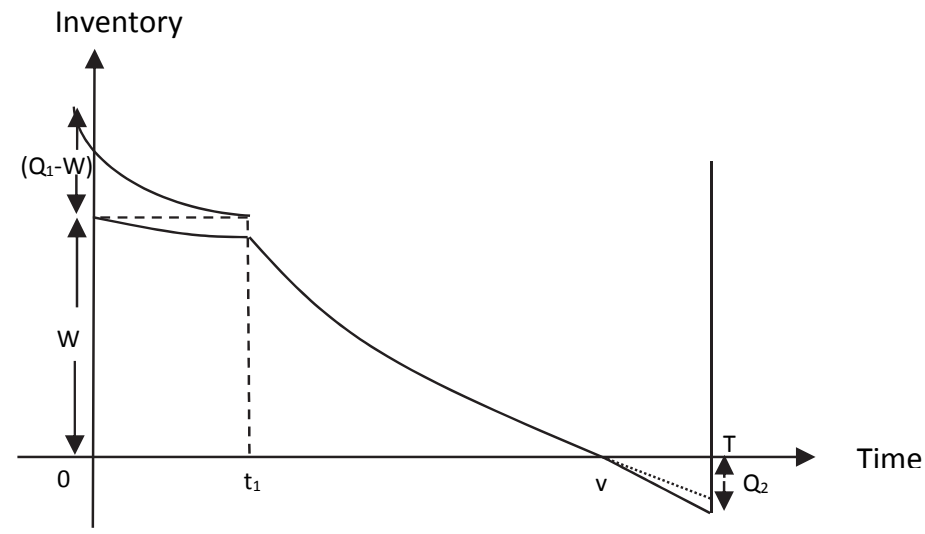

Fig. 1. Inventory time graph of two warehouse inventory model 
Differential equations showing the behavior of inventory with time are as follows:

$$
\frac{d I_{r}(t)}{d t}=-K I_{r}(t)-(a-b s) \quad 0 \leq t \leq t_{1}
$$

with boundary condition $I_{r}\left(t_{1}\right)=0$

$$
\frac{d I_{o}(t)}{d t}=-K I_{o}(t) \quad 0 \leq t \leq t_{1}
$$

with boundary condition $I_{o}(0)=W$

$$
\frac{d I_{o}(t)}{d t}=-K I_{o}(t)-(a-b s) \quad t_{1} \leq t \leq v
$$

with boundary condition $I_{o}(v)=0$

Solution of the above mentioned differential equations are given by:

$$
\begin{array}{ll}
I_{r}(t)=\frac{(a-b s)}{K}\left(e^{K\left(t_{1}-t\right)}-1\right) & 0 \leq t \leq t_{1} \\
I_{o}(t)=W e^{-K t} & 0 \leq t \leq t_{1} \\
I_{o}(t)=\frac{(a-b s)}{K}\left(e^{K(v-t)}-1\right) & t_{1} \leq t \leq v
\end{array}
$$

At initial stage an order of $Q_{1}+Q_{2}$ units is made out of which the $Q_{2}$ units are used to meet the backordered quantity and the remaining $Q_{1}$ units are stored as the initial stock level for next cycle. Since the owned warehouse has a limited capacity of $W$ units, so if the stock level $Q_{1} \geq W$, then the remaining quantity $\left(Q_{1}-W\right)$ will be stored in rented warehouse.

From Eq. (5) we know that:

$$
\begin{aligned}
& I_{r}(0)=\left(Q_{1}-W\right) \\
& Q_{1}=W+\frac{(a-b s)}{K}\left(e^{K t_{1}}-1\right)
\end{aligned}
$$

From Eq. (5) and Eq. (6):

$$
W=\frac{(a-b s)}{K}\left(e^{K v}-e^{K t_{1}}\right)
$$

Since $\mathrm{K}<<1$

So by solving Eq. (8) we get:

$$
t_{1}=v-\frac{W}{(a-b s)}
$$

\section{Different Associated Costs}

Purchasing Cost

Since $Q_{1}$ is the initial stock level and $Q_{2}$ is the backordered quantity. So the purchasing cost will be:

P.C. $=\left(Q_{1}+Q_{2}\right) p$

where $Q_{1}$ is given in Eq. (7) and $Q_{2}$ can be calculated as follow: 
$Q_{2}=\int_{v}^{T} \theta(a-b s) d t$

$Q_{2}=(a-b s) \theta(T-v)$

Then purchasing cost will be

$$
\text { P.C. }=\left\{\left(W+\frac{(a-b s)}{K}\left(e^{K t_{1}}-1\right)\right)+(a-b s) \theta(T-v)\right\} p
$$

\section{Holding Cost}

The stock is stored in owned warehouse and rented warehouse.

$$
H . C_{R}=h_{r} \int_{0}^{t_{1}} I_{r}(t) d t=h_{r} \frac{(a-b s)}{K}\left(\frac{e^{K t_{1}}-1}{K}-t_{1}\right)
$$

and

$$
H . C_{o}=h_{o}\left\{\int_{0}^{t_{1}} I_{o}(t) d t+\int_{t_{1}}^{v} I_{o}(t) d t\right\}=\frac{W h_{0}}{K}\left(1-e^{-K t_{1}}\right)+h_{o} \frac{(a-b s)}{K}\left(\frac{e^{K\left(v-t_{1}\right)}-1}{K}+\left(t_{1}-v\right)\right)
$$

Deterioration Cost

The stock of items is stored in owned warehouse and in rented warehouse so the deterioration will occur in both the places. Here $\mathrm{D}\left[0, \mathrm{t}_{1}\right]$ denotes the demand during $\left[0, \mathrm{t}_{1}\right]$.

$D \cdot C_{R}=d\left(I_{r}(0)-D\left[0, t_{1}\right]\right)$

$$
D . C_{R}=d\left\{\frac{a-b s}{K}\left(e^{K t_{1}}-1\right)-(a-b s) t_{1}\right\}
$$

and

$D \cdot C_{o}=d\left(W-D\left[t_{1}, v\right]\right)$

$$
\text { D. } C_{o}=d\left\{W-(a-b s)\left(v-t_{1}\right)\right\}
$$

\section{Shortage Cost}

The shortage cost during the shortage period $[v, \mathrm{~T}]$ is

$$
\text { S.C. }=c_{2} \int_{v}^{T}(a-b s) d t=c_{2}(a-b s)(T-v)
$$

\section{Lost Sale Cost}

The lost sale cost due to the partial backlogging during stock out is given by:

$$
\text { L.S.C. }=c_{3} \int_{v}^{T}(1-\theta)(a-b s) d t=c_{3}(1-\theta)(a-b s)(T-v)
$$

Now the T.A.C. for the presented model during a given cycle is:

$$
\text { T.A.C }(v, T)=\frac{1}{T}\left[\text { P.C. }+ \text { H.C. }{ }_{R}+H . C_{o}+D . C_{R}+\text { D.C. } o \text { +S.C. }+ \text { L.S.C. }\right]
$$


Here T.A.C. is a function of two variables ' $v$ ' and ' $T$ '. So to compute the minimum value of T.A.C. we have to compute optimal value of ' $\mathrm{v}$ ' and ' $\mathrm{T}$ '. For optimal value of $\mathrm{v}$ and $\mathrm{T}$

$$
\begin{aligned}
& \frac{\partial T \cdot A \cdot C .}{\partial v}=0 \quad \text { and } \quad \frac{\partial T \cdot A \cdot C .}{\partial T}=0 \\
& \frac{\partial^{2} T \cdot A \cdot C .}{\partial v^{2}}>0, \frac{\partial^{2} T \cdot A \cdot C .}{\partial T^{2}}>0 \text { and }\left(\frac{\partial^{2} T \cdot A \cdot C .}{\partial v^{2}}\right)\left(\frac{\partial^{2} T \cdot A \cdot C .}{\partial T^{2}}\right)-\left(\frac{\partial^{2} T \cdot A \cdot C .}{\partial v \partial T}\right)^{2}>0
\end{aligned}
$$

With the help of these equations, optimal values of T, $v$ and T.A.C. can be found. The below mentioned Fig.2 presents that model is convex.

\section{Numerical Example}

A numerical example is demonstrated with the help of following input parameters.

$a=50$ units, $b=0.5, s=30 \mathrm{rs} /$ unit $, \theta=0.8, c_{2}=10 \mathrm{rs} /$ unit,$c_{3}=17 \mathrm{rs} /$ unit,$p=15 \mathrm{rs} /$ unit $K=0.005, W=100$ units, $d=16 r s /$ unit,$h_{r}=0.06 r s /$ unit,$h_{o}=0.05 r s /$ unit

Corresponding to these input values, optimal values of ' $v$ ' \& ' $T$ ' are $\mathbf{5 0 . 7 2 3 8}$ days and $\mathbf{6 1 . 6 3 0 4}$ days, respectively and with the minimum value of T.A.C. is 732.828 rs.

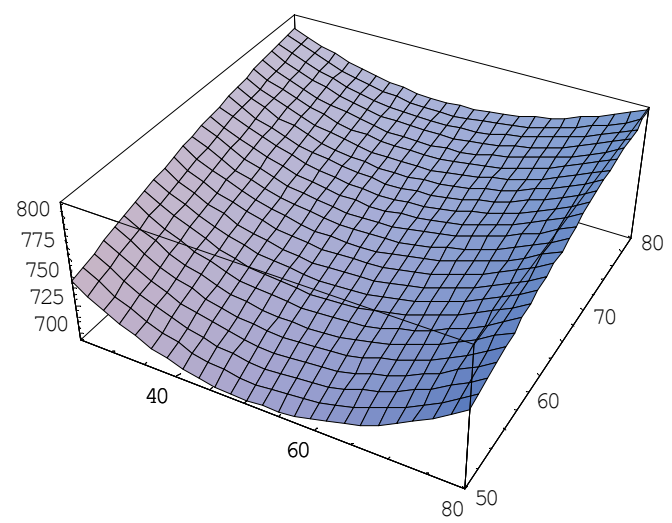

Fig. 2.Convexity of the T.A.C. function

\section{Sensitivity Analysis}

With regard to various associated parameters a sensitivity analysis is given which is shown below numerically as well as graphically.

\section{Table 1}

Effect on optimal solution for distinct values of demand parameter (a)

\begin{tabular}{ccccc}
\hline \% change in a & a & T & v & T.A.C. \\
\hline$-20 \%$ & 40 & 62.7952 & 51.6636 & 521.821 \\
$-15 \%$ & 42.5 & 62.4246 & 51.3646 & 574.563 \\
$-10 \%$ & 45 & 62.1158 & 51.154 & 627.313 \\
$-5 \%$ & 47.5 & 61.8545 & 50.9046 & 680.068 \\
$0 \%$ & 50 & 61.6304 & 50.7238 & 732.828 \\
$5 \%$ & 52.5 & 61.4362 & 50.5671 & 785.592 \\
$10 \%$ & 55 & 61.2663 & 50.43 & 838.36 \\
$15 \%$ & 57.5 & 61.1163 & 50.309 & 891.129 \\
$20 \%$ & 60 & 60.983 & 50.2015 & 943.901 \\
\hline
\end{tabular}




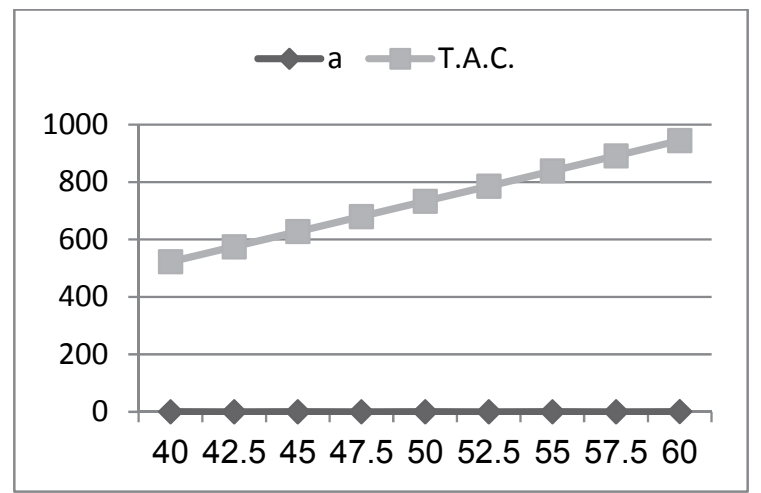

Fig. 3.Variation in total average cost w.r.t. demand parameter (a)

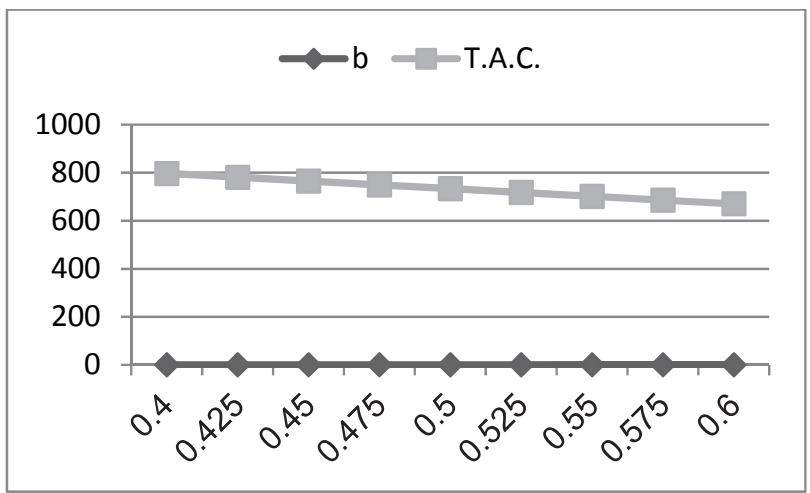

Fig. 4. Variation in total average cost w.r.t. demand parameter $(b)$

Table 2

Effect on optimal solution for distinct values of demand parameter (b)

\begin{tabular}{ccccc}
\hline \% change in b & b & T & v & T.A.C. \\
\hline$-20 \%$ & 0.4 & 61.4004 & 50.5383 & 796.145 \\
$-15 \%$ & 0.425 & 61.4545 & 50.5819 & 780.316 \\
$-10 \%$ & 0.45 & 61.5107 & 50.6272 & 764.486 \\
$-5 \%$ & 0.475 & 61.5693 & 50.6745 & 748.657 \\
$0 \%$ & 0.5 & 61.6304 & 50.7238 & 732.828 \\
$5 \%$ & 0.525 & 61.6942 & 50.7753 & 717 \\
$10 \%$ & 0.55 & 61.7608 & 50.829 & 701.172 \\
$15 \%$ & 0.575 & 61.8305 & 50.8853 & 685.344 \\
$20 \%$ & 0.6 & 61.9035 & 50.9441 & 669.517 \\
\hline
\end{tabular}

Table 3

Effect on optimal solution for distinct values of deterioration parameter (K)

\begin{tabular}{ccccc}
\hline \% change in K & K & T & v & T.A.C. \\
\hline$-20 \%$ & 0.004 & 71.6109 & 58.7761 & 731.263 \\
$-15 \%$ & 0.00425 & 68.8137 & 56.5193 & 731.653 \\
$-10 \%$ & 0.0045 & 66.2335 & 54.4376 & 732.044 \\
$-5 \%$ & 0.00475 & 63.846 & 52.5114 & 732.436 \\
$0 \%$ & 0.005 & 61.6304 & 50.7238 & 732.828 \\
$5 \%$ & 0.00525 & 59.5688 & 49.0605 & 733.222 \\
$10 \%$ & 0.0055 & 57.6457 & 47.5089 & 733.617 \\
$15 \%$ & 0.00575 & 55.8475 & 46.0581 & 734.013 \\
$20 \%$ & 0.006 & 54.1625 & 44.6986 & 734.41 \\
\hline
\end{tabular}

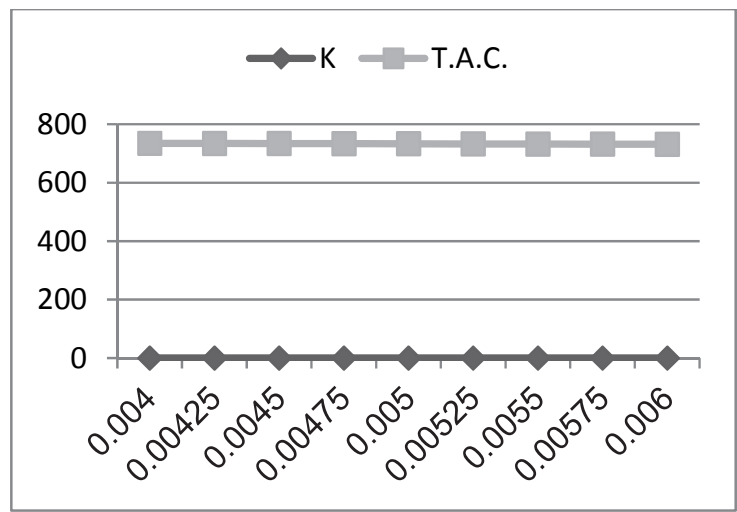

Fig. 5. Variation in total average cost w.r.t. deterioration parameter $(\mathrm{K})$

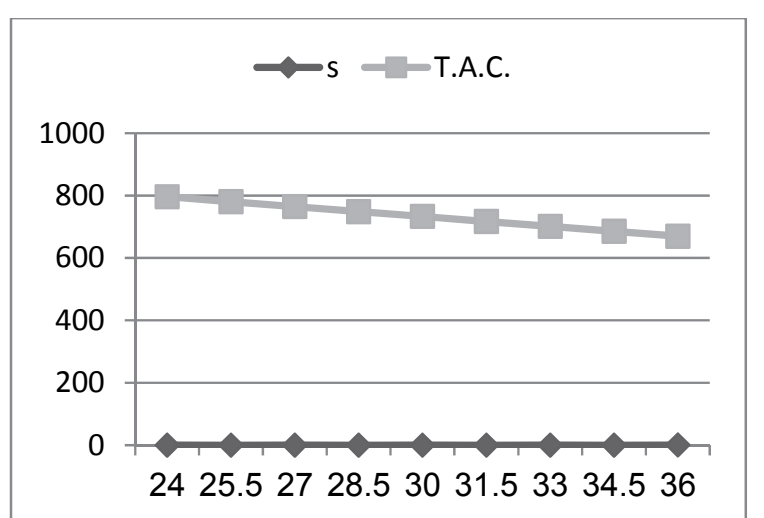

Fig. 6.Variation in total average cost w.r.t. selling price (s) 
Table 4

Effect on optimal solution for distinct values of selling price (s)

\begin{tabular}{ccccc}
\hline \% change in s & s & T & v & T.A.C. \\
\hline$-20 \%$ & 24 & 61.4004 & 50.5383 & 796.145 \\
$-15 \%$ & 25.5 & 61.4545 & 50.5819 & 780.316 \\
$-10 \%$ & 27 & 61.5107 & 50.6272 & 764.486 \\
$-5 \%$ & 28.5 & 61.5693 & 50.6745 & 748.657 \\
$0 \%$ & 30 & 61.6304 & 50.7238 & 732.828 \\
$5 \%$ & 31.5 & 61.6942 & 50.7753 & 717 \\
$10 \%$ & 33 & 61.7608 & 50.829 & 701.172 \\
$15 \%$ & 34.5 & 61.8305 & 50.8853 & 685.344 \\
$20 \%$ & 36 & 61.9035 & 50.9441 & 669.517 \\
\hline
\end{tabular}

Table 5

Effect on optimal solution for distinct values of backlogging parameter $(\theta)$

\begin{tabular}{ccccc}
\hline \% change in $\boldsymbol{\theta}$ & $\boldsymbol{\theta}$ & $\boldsymbol{T}$ & $\mathbf{v}$ & T.A.C. \\
\hline$-20 \%$ & 0.64 & 63.4813 & 52.2171 & 739.501 \\
$-15 \%$ & 0.68 & 63.0186 & 51.8438 & 737.833 \\
$-10 \%$ & 0.72 & 62.5559 & 51.4705 & 736.165 \\
$-5 \%$ & 0.76 & 62.0931 & 51.0971 & 734.496 \\
$0 \%$ & 0.8 & 61.6304 & 50.7238 & 732.828 \\
$5 \%$ & 0.84 & 61.1677 & 50.3505 & 731.16 \\
$10 \%$ & 0.88 & 60.7049 & 49.9771 & 729.492 \\
$15 \%$ & 0.92 & 60.2422 & 49.6038 & 727.824 \\
$20 \%$ & 0.96 & $59 . .7795$ & 49.2305 & 726.156 \\
\hline
\end{tabular}

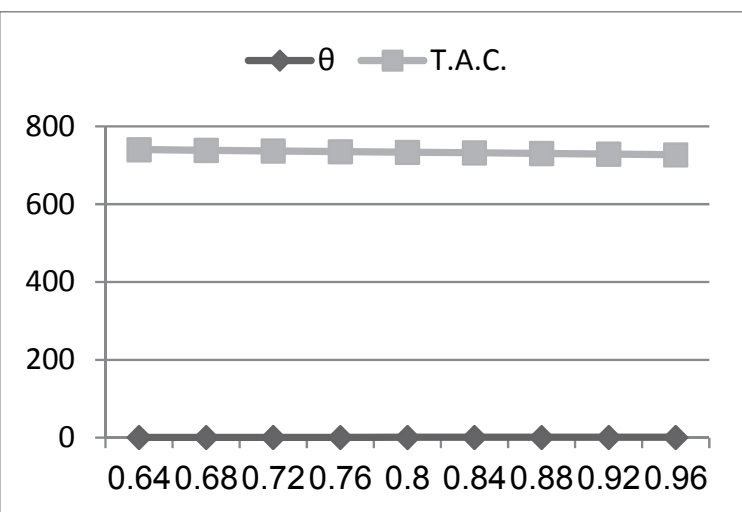

Fig. 7.Variation in total average cost w.r.t. backlogging parameter $(\theta)$

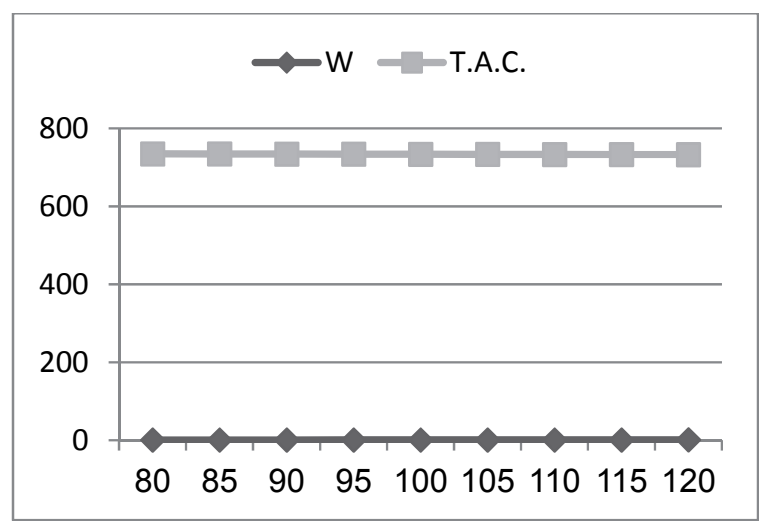

Fig. 8.Variation in total average cost w.r.t. warehouse capacity $(\mathrm{W})$

\section{Table 6}

Effect on optimal solution for distinct values of warehouse capacity (W)

\begin{tabular}{ccccc}
\hline \% change in W & W & T & v & T.A.C. \\
\hline$-20 \%$ & 80 & 61.0478 & 50.2537 & 734.012 \\
$-15 \%$ & 85 & 61.1934 & 50.3713 & 733.713 \\
$-10 \%$ & 90 & 61.3391 & 50.4888 & 733.416 \\
$-5 \%$ & 95 & 61.4848 & 50.6063 & 733.122 \\
$0 \%$ & 100 & 61.6304 & 50.7238 & 732.828 \\
$5 \%$ & 105 & 61.776 & 50.8413 & 732.537 \\
$10 \%$ & 110 & 61.9217 & 50.9588 & 732.248 \\
$15 \%$ & 115 & 62.0673 & 51.0763 & 731.96 \\
$20 \%$ & 120 & 62.2129 & 51.1937 & 731.674 \\
\hline
\end{tabular}




\section{Observations}

1. Table 1 shows the effect of demand parameter (a) on v, T and on T.A.C. From this, we have noticed that an increase in demand parameter (a) shows a reverse effect of decrement in $v$ and $T$ and the same effect of increment in T.A.C.

2. Table 2 presents the effect of demand parameter ' $b$ ' on $v, T$ and on T.A.C. It is noticed that with an increment in demand parameter ' $b$ ', values of ' $v$ ' and ' $T$ ' increase while value of T.A.C. decreases.

3. Table 3 shows the deviation of deterioration parameter $(K)$ at distinct points and it is noticed that as deterioration parameter $(\theta)$ increases, the values of ' $\mathrm{v}$ ' and ' $\mathrm{T}$ ' decrease while T.A.C. increases.

4. Table 4 lists the variation in selling price's' and from this, we have noticed that an increment in selling price shows maintains a reverse effect of decrement in T.A.C.

5. Table 5 presents the deviation of backlogging parameter $(\theta)$ at distinct points and it is noticed that as backlogging parameter $(\theta)$ increases, the values of $v, T$ and T.A.C. decrease.

6. In Table 6 the variation in stock capacity (W) of owned warehouse is discussed. Here it is shown that with an increase in capacity of the owned warehouse the T.A.C. of the system gradually decreases.

\section{Conclusion}

The main motive of the development of inventory model is to find out that the quantity and the time of order, which can optimize the total average cost of the system. Due to offered concession in bulk purchasing and different conditions the vendor purchases the quantity greater than the warehouse capacity. So in this condition vendor has to stock the extra quantity in any rented warehouse. Keeping in mind that the inventory cost such as holding cost in R.W. is higher than that of O.W. this paper has presented a significant outcome that additional cost of safeguarding and holding material etc. could be reduced using the proposed method. But in order to reduce the inventory cost, it will be more realistic and profitable for organizations to store items in O.W. before R.W., but utilize the stocks in R.W. before O.W.

From this analysis it is concluded that an increase capacity of O.W. decreases total system cost. Shortages are permitted in this model and the occurring shortages are partially backlogged. The convexity of total average cost function has also been presented. For future scope, the model can be developed with trade credit period, stock dependent demand, time value of money and many more. Also the inventory holding cost, the unit purchase cost, and others cost can be considered as dependent upon time. A numerical example and sensitivity analysis with respect to various system parameters is also presented.

\section{References}

Agrawal, S., Banerjee, S., \& Papachristos, S. (2013). Inventory model with deteriorating items, ramptype demand and partially backlogged shortages for a two warehouse system. Applied Mathematical Modelling, 37(20-21), 8912-8929.

Alfares, H. K., \& Ghaithan, A. M. (2016). Inventory and pricing model with price-dependent demand, time-varying holding cost, and quantity discounts. Computers \& Industrial Engineering, 94, 170177.

Bhunia, A. K., Jaggi, C. K., Sharma, A., \& Sharma, R. (2014). A two-warehouse inventory model for deteriorating items under permissible delay in payment with partial backlogging. Applied Mathematics and Computation, 232, 1125-1137.

Dave, U. (1989). A deterministic lot-size inventory model with shortage and a linear trend in demand. Naval Research Logistics, 36(4), 507-514. 
Dye, J. K., Mandal, S. K., \& Maiti, M. (2008). Two storage inventory problem with dynamic demand and interval valued lead-time over finite time horizon under inflation and time-value of money. European Journal of Operational Research, 185(1), 170-194.

Goswami, A., \& Chaudhuri, K. S. (1992). An economic order quantity model for items with two levels of storage for a linear trend in demand. Journal of Operational Research Society, 43(2), 157-167.

Hartely, V. R. (1976). Operations Research-A Managerial Emphasis. Good Year Publishing Company, California, 315-317.

Jaggi, C. K., Pareek, S., Khanna, A., \& Sharma, R. (2014). Credit financing in a two-warehouse environment for deteriorating items with price-sensitive demand and fully backlogged shortages. Applied Mathematical Modelling, 38(21-22), 5315-5333.

Jaggi, C. K., Tiwari, S., \&Shafi, A. A. (2015). Effect of deterioration on two-warehouse inventory model with imperfect quality.Computers \& Industrial Engineering, 88, 378-385.

Jaggi, C. K., \& Verma, P. (2010). Two-warehouse inventory model for deteriorating items with linear trend in demand and shortages under inflationary conditions. International Journal of Procurement Management, 3(1), 54-71.

Khanna, A., Mittal, M., Gautam, P., \& Jaggi, C. K. (2016). Credit financing for deteriorating imperfect quality items with allowable shortages. Decision Science Letters, 5(1), 45-60.

Maiti, A., Mait, M., \& Maiti, M. (2009). Inventory model with stochastic lead-time and price dependent demand incorporating advance payment. Applied Mathematical Modelling, 33(5), 2433-2443.

Mondal, B., Bhunia, A.K., \& Maiti, M. (2003). An inventory system of ameliorating items for price dependent demand rate. Computers and Industrial Engineering, 45(3), 443-456.

Ouyang, L. Y., Chen, H. C., \& Chang, H. C. (1999). Lead time and ordering cost reductions in continuous review inventory systems with partial backorders. Journal of the Operational Research Society, 50(12), 1272-1279.

Ouyang, L. Y., Wu, K. S., \& Cheng, M. C. (2005). An inventory model for deteriorating items with exponential declining demand and partial backlogging. Yugoslav Journal of Operations Research, 15(2), 277-288.

Pakkala, T. P. M., \& Achary, K. K. (1992). A deterministic inventory model for deteriorating items with two warehouses and finite replenishment rate. European Journal of Operational Research, 57(1), 71-76.

Palanivel, M., Sundararajan, R. and Uthayakumar. (2016). Two warehouse inventory model with noninstantaneously deteriorating items, stock dependent demand, shortages and inflation. Journal of Management Analytics, 3(2), 152-173.

San-José, L.A., Sicilia, J., \& García-Laguna, J. (2015). Analysis of an EOQ inventory model with partial backordering and non-linear unit holding cost. Omega, 54, 147-157.

Sett, B. K., Sarkar, B., \& Goswami, A. (2012). A two warehouse inventory model with increasing demand and time varying deterioration. Scientia Iranica, 19(6), 1969-1977.

Sharma, S., Singh, S.R., \& Ram, M. (2015). An EPQ model for deteriorating items with price sensitive demand and shortages. International Journal of Operational Research, 23(2), 245-255.

Shastri, A., Singh, S. R., \& Gupta, S. (2015). Supply chain management under the effect of trade credit for deteriorating items with ramp-type demand and partial backordering under inflationary environment. Uncertain Supply Chain Management, 3(4), 339-362.

Skouri, K., Konstantaras, I., Papachristos, S., \& Ganas, I. (2009). Inventory models with ramp type demand rate, partial backlogging and Weibull deterioration rate. European Journal of Operational Research, 192(1), 79- 92.

Singh, S. R., Jain, S., \& Pareek, S. (2013). An imperfect quality items with learning and inflation under two limited storage capacity. International Journal of Industrial Engineering Computations, 4(4), 479-490.

Singh, S. R., Kumar, N., \& Kumari, R. (2009). Two-warehouse inventory model for deteriorating items with shortages under inflation and time-value of Money. International Journal of Computational and Applied Mathematics, 4(1), 83-94. 
Singh, S. R., Kumar, T., \& Gupta, C. B. (2011). A soft computing based inventory model with deterioration and price dependent demand. International Journal of Computer Applications, 36(4), 10-17.

Singh, S. R., \& Singh, T. J. (2007). An EOQ inventory model with Weibull distribution deterioration, ramp type demand and partial backlogging. Indian Journal of Mathematics and Mathematical Sciences, 3(2), 127-137.

Taleizadeh, A. A., \& Pentico, D. W. (2013). An economic order quantity model with a known price increase and partial back ordering. European Journal of Operational Research, 228(3), 516-525.

Tayal, S., Singh, S. R., \& Sharma, R. (2015). An inventory model for deteriorating items with seasonal products and an option of an alternative market. Uncertain Supply Chain Management, 3(1), 69-86.

Tayal, S., Singh, S. R., Sharma, R., \& Chauhan, A. (2014). Two echelon supply chain model for deteriorating items with effective investment in preservation technology. International Journal of Mathematics in Operational Research, 6(1), 84-105.

Wee, H. M. (1997). A replenishment policy for items with a price-dependent demand and a varying rate of deterioration. Production Planning \& Control, 8(5), 494-499.

Yang, H. L. (2004). Two-warehouse inventory models for deteriorating items with shortages under inflation. European Journal of Operational Research, 157(2), 344-356.

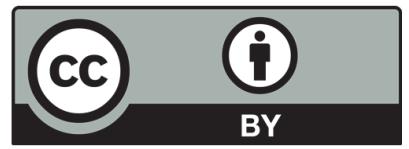

(C) 2016 by the authors; licensee Growing Science, Canada. This is an open access article distributed under the terms and conditions of the Creative Commons Attribution (CC-BY) license (http://creativecommons.org/licenses/by/4.0/). 